\title{
Appropriateness of Apixaban Dosing to Prevent Stroke in Patients with Atrial Fibrillation: A Pilot Study
}

\author{
Stephanie Carlin, Jennifer Pickering, and Sam Schulman
}

\begin{abstract}
Background: The ARISTOTLE study investigated apixaban, at a dose of $5 \mathrm{mg}$ PO bid, for the prevention of stroke in patients with atrial fibrillation; however, it has been noted anecdotally that many patients are receiving $2.5 \mathrm{mg}$ PO bid, despite being eligible for the full dosage. A recent study examining the use of dabigatran and rivaroxaban found that many patients were receiving these medications inappropriately; however, a literature search conducted in April 2016 showed that apixaban had not been formally studied in this context.

Objective: To evaluate the appropriateness of apixaban dosing for stroke prevention in patients with atrial fibrillation, relative to the dose used in the ARISTOTLE study and recommendations in the product monograph.

Methods: This retrospective chart review was conducted at a 300-bed Canadian teaching hospital. All inpatients with atrial fibrillation for whom apixaban was prescribed for stroke prevention in March 2015 were considered for inclusion. The appropriateness of apixaban dosing was determined in relation to the ARISTOTLE methodology and product monograph recommendations (i.e., $5 \mathrm{mg}$ PO bid, with a lower dosage of $2.5 \mathrm{mg}$ PO bid if warranted on the basis of age, weight, or serum creatinine level).

Results: A total of 47 patients were included, of whom 25 (53\%) were receiving apixaban inconsistent with the ARISTOTLE study and the product monograph. Limitations of the current study included small sample size, single-centre setting, and retrospective design, which precluded determination of each prescriber's rationale for dosage choice.

Conclusions: Pharmacists and physicians should be vigilant in ensuring that patients with atrial fibrillation are receiving the appropriate dosage of apixaban to optimize the risk-benefit ratio of this therapy.
\end{abstract}

Keywords: apixaban, anticoagulation, atrial fibrillation, stroke, evaluation of medication utilization

\section{RÉSUMÉ}

Contexte : L'étude ARISTOTLE portait sur l'utilisation de l'apixaban pour la prévention des accidents vasculaires cérébraux (AVC) chez les patients souffrant de fibrillation auriculaire à raison d'une dose de $5 \mathrm{mg}$ par voie orale deux fois par jour. Or, des observations empiriques montrent que bon nombre de patients reçoivent une dose de $2,5 \mathrm{mg}$ par voie orale deux fois par jour, même s'ils se qualifient pour la pleine dose. Une étude récente portant sur l'utilisation du dabigatran et du rivaroxaban a relevé que bon nombre de patients recevaient ces médicaments de façon inappropriée. Or, une recherche bibliographique effectuée en avril 2016 a révélé que l'apixaban n'a pas été officiellement étudié dans ce contexte.

Objectif : Évaluer la pertinence du schéma posologique d'apixaban pour la prévention des AVC chez les patients souffrant de fibrillation auriculaire comparativement à la dose utilisée dans l'étude ARISTOTLE et aux recommandations contenues dans la monographie de produit.

Méthodes : La présente analyse rétrospective de dossiers médicaux a été menée dans un seul centre hospitalier universitaire canadien de 300 lits. Tous les patients hospitalisés atteints de fibrillation auriculaire pour qui l'on a prescrit de l'apixaban afin de prévenir l'AVC en mars 2015 ont été pris en considération. La pertinence du schéma posologique d'apixaban était établie par rapport à la méthodologie de l'étude ARISTOTLE et aux recommandations de la monographie de produit (c'est-à-dire une dose de $5 \mathrm{mg}$ par voie orale deux fois par jour et une dose réduite de 2,5 mg par voie orale deux fois par jour si l'âge, le poids et le taux de créatinine sérique la justifiaient).

Résultats : Au total, 47 patients ont été admis. L'administration de l'apixaban n'était pas conforme à l'étude ARISTOTLE et à la monographie de produit chez 25 (53\%) d'entre eux. Parmi les limites de la présente étude, on comptait la petite taille de l'échantillon, son déroulement dans un seul centre et l'utilisation d'un plan d'étude rétrospectif qui empêchait de comprendre les raisons motivant le choix de posologie de chaque prescripteur.

Conclusions : Les pharmaciens et les médecins doivent être vigilants et s'assurer que les patients atteints de fibrillation auriculaire reçoivent la posologie appropriée d'apixaban permettant d'optimiser le rapport bénéfice-risque de ce traitement.

Mots clés : apixaban, anticoagulothérapie, fibrillation auriculaire, accident vasculaire cérébral, évaluation de l'utilisation des médicaments 


\section{INTRODUCTION}

A trial fibrillation is a supraventricular arrhythmia that puts patients at increased risk of stroke. Anticoagulation is recommended for patients with a score of 1 or higher on the $\mathrm{CHADS}_{2}$ scale, a clinical prediction tool that is used to estimate the risk of stroke (where 1 point is assigned for each of congestive heart failure, hypertension, age 75 years or older, and diabetes mellitus, and 2 points are assigned for prior ischemic stroke or transient ischemic attack). ${ }^{1}$ The 2014 Canadian Cardiovascular Society guidelines for atrial fibrillation recommend the use of a direct oral anticoagulant (dabigatran, rivaroxaban, or apixaban) over warfarin. ${ }^{2}$ In the Apixaban Versus Warfarin in Patients with Atrial Fibrillation (ARISTOTLE) trial, apixaban was found to be superior to warfarin for preventing strokes and resulted in a decreased risk of bleeding. ${ }^{3}$ Stroke registry data in Ontario showed that for up to $75 \%$ of high-risk patients with atrial fibrillation who were admitted to hospital with a stroke and who were taking warfarin at the time of admission, the international normalized ratio (INR) was subtherapeutic. ${ }^{4}$ Direct-acting oral anticoagulants such as apixaban, which are much simpler to dose, do not require INR monitoring, and are associated with fewer drug and food interactions, have therefore become more attractive options for many clinicians and patients.

Apixaban for stroke prevention in atrial fibrillation was studied at a dose of $5 \mathrm{mg}$ PO bid (with a lower dose of $2.5 \mathrm{mg}$ PO bid for a small number of patients who met specific selection criteria) in the ARISTOTLE trial, ${ }^{3}$ and this is the dosage recommended in the product monograph. ${ }^{5}$ Despite these dosage recommendations, it was noted anecdotally by pharmacists at the study hospital that the lower dose of this medication was prescribed for certain patients on admission to hospital, in accordance with their home regimen, or the lower dose was ordered in hospital despite the patient being eligible for the full dosage, which has been proven to reduce the risk of stroke. In a recent study, $49 \%$ of patients were receiving dabigatran or rivaroxaban inappropriately as a result of, among other reasons, inappropriate medication choice, prescription of the wrong dosage, or improper administration (e.g., rivaroxaban taken on an empty stomach). ${ }^{6}$ In another study, $19 \%$ of patients were receiving an inappropriate dose of a direct oral anticoagulant, and an additional $14 \%$ were using their direct oral anticoagulants inappropriately. ${ }^{7}$ However, a literature search conducted in April 2016 revealed that the appropriateness of apixaban prescribing had not been specifically evaluated.

This study was conducted to assess the appropriateness of apixaban dosing for stroke prevention in patients with atrial fibrillation in a large urban teaching hospital.

\section{METHODS}

This retrospective chart review was conducted at the Hamilton General Hospital, a 300-bed teaching hospital providing specialty cardiac, stroke, and trauma care, and involved patients with atrial fibrillation who were receiving apixaban for stroke prevention. All patients with atrial fibrillation who received an in-hospital prescription for apixaban for stroke prevention between March 1 and March 31, 2015, were considered for inclusion. Patients may or may not have been receiving apixaban before their admission. Eligible patients were identified by one of the authors (S.C.) through examination of prescription records in the pharmacy module of the institution's electronic medical record system (Meditech, Medical Information Technology, Inc, Westwood, Massachusetts). Study data were gathered by the same author (S.C.) through other Meditech modules and Sovera software (CGI Technologies and Solutions, Montréal, Quebec) containing scanned patient charts. The diagnosis of atrial fibrillation was confirmed through physician dictation or admission notes in either the Meditech or the Sovera system. Patients were excluded for the following reasons: no diagnosis of atrial flutter or atrial fibrillation, lack of documentation of patient weight, or no apixaban received at the study institution.

The appropriateness of apixaban dosing was determined in relation to the criteria used in the ARISTOTLE trial and the corresponding recommendation in the product monograph: $5 \mathrm{mg}$ PO bid or a lower dose (2.5 mg PO bid) only if the patient meets 2 or more of the following criteria: age 80 years or older, body weight less than $60 \mathrm{~kg}$, and serum creatinine of $133 \mu \mathrm{mol} / \mathrm{L}$ or above. Patients were deemed to be receiving apixaban inconsistent with the ARISTOTLE study if creatinine clearance $(\mathrm{CrCl})$, calculated with the Cockcroft-Gault formula, was less than $25 \mathrm{~mL} / \mathrm{min}$, as patients with renal function below this threshold were excluded from the ARISTOTLE study.

If a patient's prescription for apixaban differed from the dosage used in the ARISTOTLE study and recommended in the product monograph, and a rationale for the alternative dosing was stated or implied in the patient chart, determination of "appropriateness" of the rationale was reached through consensus by the authors of the current study (S.C., J.P. [pharmacists], and S.S. [thromboembolism physician]). Appropriateness was established if, in the opinion of the authors, the risk-benefit ratio of the prescribed apixaban dose was more favourable than that of the recommended dose. The study received approval from the Hamilton Integrated Research Ethics Board.

\section{RESULTS}

A total of 57 patients were identified through pharmacy dispensing records, of whom 10 were excluded, which resulted in a total of 47 included patients with evaluable data. The patients ranged in age from 54 to 96 years, the sample was evenly split between men and women, and the median $\mathrm{CHADS}_{2}$ score was 3 (Table 1).

For a total of 28 patients (60\%), the dosage of apixaban prescribed in hospital was $2.5 \mathrm{mg}$ PO bid, whereas the dosage 
This single copy is for your personal, non-commercial use only.

For permission to reprint multiple copies or to order presentation-ready copies for distribution, contact CJHP at cjhpedit@cshp.ca

Table 1. Baseline Characteristics of Patients with Atrial Fibrillation Who Received Apixaban during Hospitalization

\begin{tabular}{|c|c|}
\hline Characteristic & $\begin{array}{c}\text { No. (\%) of Patients* } \\
(n=47)\end{array}$ \\
\hline Age (years) (median and range) & $83(54-96)$ \\
\hline Sex, female & $24(51)$ \\
\hline Weight (kg) (median and range) & $68(53-121)$ \\
\hline Serum creatinine $(\mu \mathrm{mol} / \mathrm{L})($ mean $\pm \mathrm{SD})$ & $92.9 \pm 30.1$ \\
\hline Creatinine clearance $(\mathrm{mL} / \mathrm{min})($ mean $\pm \mathrm{SD})$ & $48.4 \pm 21.6$ \\
\hline Heart failure or left ventricular ejection fraction $<40 \%$ & $26(55)$ \\
\hline Age $\geq 75$ years & $36(77)$ \\
\hline Diabetes mellitus & $16(34)$ \\
\hline Prior transient ischemic attack/stroke & $14(30)$ \\
\hline $\mathrm{CHADS}_{2}$ score (median and range) & $3(1-6)$ \\
\hline \multicolumn{2}{|l|}{ Concurrent medications } \\
\hline Acetylsalicylic acid & $17(36)$ \\
\hline Clopidogrel, prasugrel, or ticagrelor & $6(13)$ \\
\hline Dual antiplatelet therapy & $5(11)$ \\
\hline
\end{tabular}

$\mathrm{CHADS}_{2}=$ score based on congestive heart failure, hypertension, age $\geq 75$ years, diabetes mellitus, prior ischemic stroke, transient ischemic attack; SD = standard deviation.

*Except where indicated otherwise.

was $5 \mathrm{mg}$ PO bid for the remaining 19 patients (40\%). Overall, $25(53 \%)$ of the patients were receiving apixaban or a particular dose of apixaban that was inconsistent with the ARISTOTLE trial and the product monograph (Table 2).

A total of 6 (24\%) of these 25 patients had a prescription for apixaban despite a $\mathrm{CrCl}(<25 \mathrm{~mL} / \mathrm{min})$ that would have excluded them from the ARISTOTLE trial. The product monograph ${ }^{5}$ states that, because of limited clinical data, dosing recommendations cannot be made for patients with $\mathrm{CrCl}$ between 15 and $24 \mathrm{~mL} / \mathrm{min}$.

A total of $19(76 \%)$ of the 25 patients had a prescription for the lower dose of apixaban (2.5 mg PO bid) despite being eligible for the higher dose ( $5 \mathrm{mg}$ PO bid), according to criteria of the ARISTOTLE study. The mean age of these 19 patients was 83 years, 10 (53\%) were women, and the mean $\mathrm{CHADS}_{2}$ score was 3.3. Nine of these patients (19\% of the entire sample) were receiving the lower dose of apixaban with no obvious rationale stated or implied, whereas $10(21 \%$ of the entire sample) were receiving the lower dose with a stated or implied rationale. After reviewing the 10 cases with a stated or implied rationale, the 3 authors deemed the rationale to be reasonable for 7 patients; for the other 3 patients, the rationale was thought to be potentially lacking sufficient justification for use of the lower dose. However, because the study was a retrospective chart audit, the prescriber's rationale could not be confirmed in these cases.

Of the 19 patients ( $76 \%$ of the total sample) with prescribed dosage of apixaban inconsistent with the ARISTOTLE study and the product monograph, $11(58 \%)$ had been receiving this dosage at the time of admission to hospital. For only $1(9 \%)$ of these 11 was the dosage increased while in hospital.

\section{DISCUSSION}

This study has confirmed the observation that a considerable number of patients with atrial fibrillation who are receiving apixaban for stroke prevention have prescriptions that are inconsistent with the ARISTOTLE study or are receiving a dose lower than that investigated in the ARISTOTLE study and recommended in the product monograph. This finding is consistent, albeit with a greater incidence, with findings in the study by Larock and others, ${ }^{6}$ in which $26 \%$ of patients were receiving an inappropriate dosage of rivaroxaban or dabigatran.

The finding that several patients with severe renal impairment were receiving apixaban, although they would have been excluded from the ARISTOTLE trial, is of importance. Apixaban has not been well studied in this population, so the risk of bleeding has not been clearly defined. The risk may be increased in these patients because of the appreciable percentage of apixaban that is excreted in the urine $(27 \%)$ and because of the lack of a readily available reversal agent.

Perhaps more importantly, patients for whom the prescribed dose of apixaban was lower than recommended are not receiving the full benefit of anticoagulation, which could translate into an increased risk of stroke. In the ARISTOTLE trial, only 831 patients ( $4.6 \%$ of the study population) were receiving apixaban or placebo at a dose of $2.5 \mathrm{mg}$ PO bid. Of these patients, 790 were 75 years of age or older, the age group representing the majority of patients in the study reported here. In analyzing the ARISTOTLE subgroup of elderly patients within the slightly larger subgroup of patients receiving $2.5 \mathrm{mg}$ PO bid, Halvorsen and others ${ }^{8}$ found no difference in rates of stroke or systemic embolism and lower rates of major bleeding between patients receiving $2.5 \mathrm{mg}$ PO bid and those receiving warfarin. However, 
Table 2. Characteristics of Apixaban Therapy

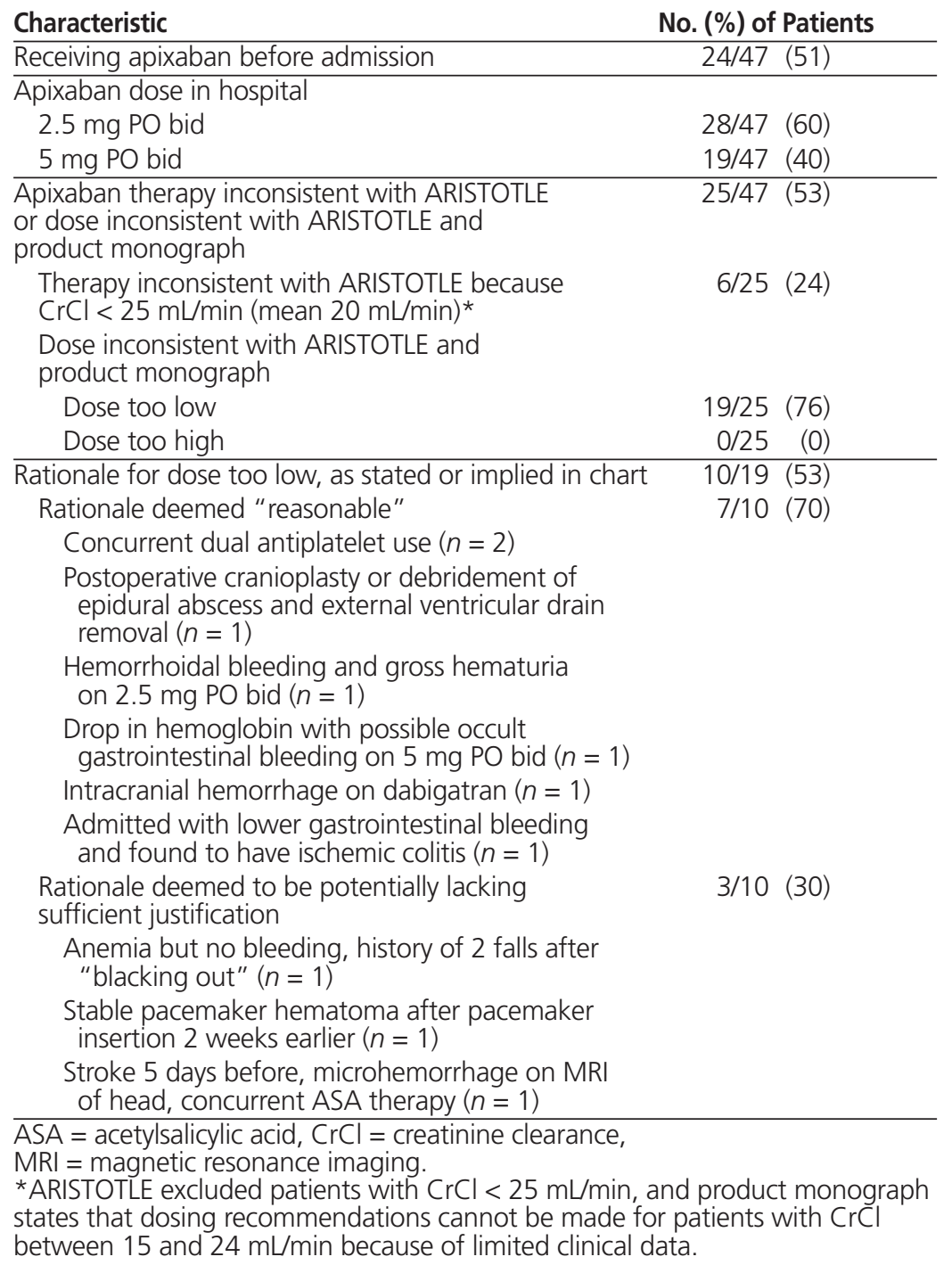

because this age-based subgroup was quite small, it is difficult to be confident that the dosage of $2.5 \mathrm{mg}$ PO bid would reduce the risk of stroke in patients who do not meet the specified criteria for this dosage. Furthermore, these data have not prompted any changes to the product monograph's dosing recommendations for this elderly population.

In the current study, many of the patients with a prescribed dose of apixaban inconsistent with recommendations had been receiving this dosage before admission. This finding may be related to findings reported by Pradhan and Levine, ${ }^{9}$ who surveyed family physicians and found that reluctance to prescribe anticoagulation (specifically warfarin) was associated with an underappreciation of the therapeutic benefits of anticoagulation and a high concern about bleeding. Interestingly, in the current study, only 1 patient who was receiving a dose of apixaban inconsistent with the recommendations before admission had a dosage increase while in hospital. This finding highlights an important role and opportunity for pharmacists and physicians to better assess the appropriateness of patients' home medications while in hospital and to use the admission as an opportunity to optimize these medications.

This study had several limitations. First, it was a small, retrospective, single-centre study. The retrospective nature of the study prevented the authors from determining whether there was a valid rationale for using a decreased dose of apixaban, except where this information was documented in the chart. As such, the percentage of patients with a valid reason for use of the lower dose may have been larger than reported here. As well, for the 3 patients deemed to have potentially inadequate justification for use of a lower dose, additional factors not evident in the chart may have strengthened the rationale for the lower dose.

According to the study methods, other medications received concurrently with apixaban were not determined from the patients' charts. Such concurrent medications might have 
resulted in increased (or decreased) apixaban concentrations, which in turn might have justified the use of a reduced (or increased) dose of apixaban; such reduced or increased doses would have appeared in our results as underdosing or overdosing, respectively. However, none of the patients' charts indicated drug interactions as a rationale for reducing (or increasing) the apixaban dose.

\section{CONCLUSION}

Several patient-specific factors were considered by prescribers in their risk-benefit analysis when deciding whether to prescribe anticoagulants for a given patient and if so, in determining the dosage. In this small pilot study, $53 \%$ of patients with atrial fibrillation were receiving apixaban inconsistent with the ARISTOTLE study and the product monograph. This discrepancy has the potential to result in an increased risk of bleeding or stroke. A prescriber's choice of a lower dose may reflect greater concern about potential bleeding complications than about potential thromboembolic events. In addition, this study suggests that a substantial proportion of patients were receiving a potentially suboptimal dosage of apixaban in the community. Community-based therapy may represent a more important prescribing deviation from the ARISTOTLE study and the product monograph and highlights an opportunity for pharmacists and physicians to improve patients' outcomes by optimizing their home medications during the hospital stay.

\section{References}

1. You JJ, Singer DE, Howard PA, Lane DA, Eckman MH, Fang MC, et al.; American College of Chest Physicians. Antithrombotic therapy for atrial fibrillation: antithrombotic therapy and prevention of thrombosis, 9th ed: American College of Chest Physicians evidence-based clinical practice guidelines. Chest. 2012;141(2 Suppl):e531S-75S.

2. Verma A, Cairns JA, Mitchell LB, Macle L, Stiell IG, Gladstone D, et al.; CCS Atrial Fibrillation Guidelines Committee. 2014 focused update of the Canadian Cardiovascular Society guidelines for the management of atrial fibrillation. Can J Cardiol. 2014;30(10):1114-30. Errata in: Can J Cardiol. 2014;30(12):1495 and Can J Cardiol. 2015;31(10):1302.

3. Granger CB, Alexander JH, McMurray JJ, Lopes RD, Hylek EM, Hanna M, et al.; ARISTOTLE Committees and Investigators. Apixaban versus warfarin in patients with atrial fibrillation. N Engl J Med. 2011;365(11):981-92.

4. Gladstone DJ, Bui E, Fang J, Laupacis A, Lindsay MP, Tu JV, et al. Potentially preventable strokes in high-risk patients with atrial fibrillation who are not adequately anticoagulated. Stroke. 2009;40(1):235-40.
5. Eliquis [apixaban]. In: Compendium of pharmaceuticals and specialties. Ottawa (ON): Canadian Pharmacists Association; 2016 [cited 2016 Apr 18]. Available from: https://www-e-therapeutics.ca/cps. Subscription required to access content.

6. Larock AS, Mullier F, Sennesael AL, Douxfils J, Devalet B, Chatelain C, et al. Appropriateness of prescribing dabigatran etexilate and rivaroxaban in patients with nonvalvular atrial fibrillation: a prospective study. Ann Pharmacother. 2014;48(10):1258-68.

7. Delaney J, Schulman S, Salib M, Panju M, Pai M. Direct-acting oral anticoagulants in the real world: insights into appropriate prescribing and medication use [abstract]. J Thromb Haemost. 2015;13 Suppl 2:91.

8. Halvorsen S, Atar D, Yang H, De Caterina R, Erol C, Garcia D, et al. Efficacy and safety of apixaban compared with warfarin according to age for stroke prevention in atrial fibrillation: observations from the ARISTOTLE trial. Eur Heart J. 2014;35(28):1864-72.

9. Pradhan AA, Levine MA. Warfarin use in atrial fibrillation: a random sample survey of family physician beliefs and preferences. Can J Clin Pharmacol. 2002;9(4):199-202.

Stephanie Carlin, BSCPhm, PharmD, ACPR, is a Clinical Pharmacist with the Cardiac and Vascular Surgery Program, Hamilton General Hospital, Hamilton, Ontario.

Jennifer Pickering, BScPhm, ACPR, is a Clinical Pharmacist with the Cardiac and Vascular Surgery Program, Hamilton General Hospital, Hamilton, Ontario.

Sam Schulman, MD, is a Professor with the Department of Medicine and the Thrombosis and Atherosclerosis Research Institute, McMaster University, Hamilton, Ontario.

Competing interests: Jennifer Pickering has received consulting and speaker's honoraria from Pfizer and Bristol Myers Squibb for activities outside the submitted work. Sam Schulman has received grants from Boehringer-Ingelheim, Baxter Healthcare, and Octapharma and personal fees from Boehringer-Ingelheim, Bristol Myers Squibb, Daiichi, and Bayer, all for activities outside the submitted work. No other competing interests were declared.

\section{Address correspondence to:}

Dr Stephanie Carlin

Cardiac and Vascular Surgery Program

Hamilton General Hospital

237 Barton Street East

Hamilton ON L8L 2X2

e-mail: carlins@hhsc.ca

Funding: None received. 